\title{
Impact on health-related quality of life and costs of managing chronic neuropathic pain in academic pain centres: Results from a one-year prospective observational Canadian study
}

\author{
J-E Tarride $\mathrm{PhD}^{1,2}$, DE Moulin $\mathrm{MD}^{3}, \mathrm{M}$ Lynch $\mathrm{MD}^{4}, \mathrm{AJ}$ Clark $\mathrm{MD}^{4}$, L Stitt $\mathrm{MSC}^{5}, \mathrm{~A}$ Gordon $\mathrm{MD}^{6}$, \\ PK Morley-Forster $\mathrm{MD}^{3}, \mathrm{H}$ Nathan $\mathrm{MD}^{7}, \mathrm{C}$ Smyth $\mathrm{MD}^{7}, \mathrm{C}$ Toth $\mathrm{MD}^{8}, \mathrm{MA}$ Ware $\mathrm{MD}^{9}$
}

\begin{abstract}
J-E Tarride, DE Moulin, M Lynch, et al. Impact on health-related quality of life and costs of managing chronic neuropathic pain in academic pain centres: Results from a one-year prospective observational Canadian study. Pain Res Manag 2015;20(6):327-333.
\end{abstract}

BACKGROUND: The management of chronic pain, including neuropathic pain $(\mathrm{NeP})$, is a major public health issue. However, there is a paucity of data evaluating pain management strategies in real-life settings. OBJECTIVE: To inform policy makers about the economic value of managing chronic $\mathrm{NeP}$ in academic centres by conducting a subeconomic assessment of a Canadian multicentre cohort study aimed at determining the long-term outcomes of the management of chronic $\mathrm{NeP}$ in academic pain centres. Specific questions regarding the economic value of this type of program were answered by a subset of patients to provide further information to policy makers.

METHODS: Baseline demographic information and several pain-related measurements were collected at baseline, three, six and 12 months in the main study. A resource use questionnaire aimed at determining NePrelated costs and the EuroQoL-5 Dimension were collected in the subset study from consenting patients. Statistical analyses were conducted to compare outcomes over time and according to responder status.

RESULTS: A total of 298 patients were evaluated in the present economic evaluation. The mean $( \pm S D)$ age of the participants was $53.7 \pm 14.0$ years, and $56 \%$ were female. At intake, the mean duration of $\mathrm{NeP}$ was $>5$ years. Statistically significant improvements in all pain and health-related quality of life outcomes were observed between the baseline and one-year visits. Use decreased over time for many health care resources (eg, visits to the emergency room decreased by one-half), which resulted in overall cost savings. CONCLUSION: The results suggest that increased access to academic pain centres should be facilitated in Canada.

Key Words: Chronic neuropathic pain; Economic evaluation; Health-related quality of life; Pain management strategy;

\section{Les effets de la qualité de vie liée à la santé et des coûts de gestion de la douleur neuropathique chronique dans des centres universitaires de la douleur : résultats d'une étude d'observation prospective canadienne d'un an}

\begin{abstract}
HISTORIQUE : La gestion de la douleur chronique, y compris la douleur neuropathique (DNe) est un important enjeu de santé publique. Cependant, peu de données évaluent les stratégies de gestion de la douleur sur le terrain.

OBJECTIF : Effectuer l'évaluation subéconomique d'une étude de cohorte multicentrique canadienne pour déterminer les résultats cliniques à long terme de la gestion de la DNe chronique dans des centres universitaires de la douleur pour éclairer les décideurs quant à la valeur économique de la gestion de la DNe chronique dans ces centres. Un sous-groupe de patients a répondu à des questions précises sur la valeur économique de ce type de programme pour fournir plus d'information aux décideurs.

MÉTHODOLOGIE : Les chercheurs ont amassé de l'information démographique de base et plusieurs mesures liées à la douleur en début d'étude et trois, six et 12 mois en cours d'étude. Ils ont colligé un questionnaire sur l'utilisation des ressources afin de déterminer les coûts liés à la DNe et ont recueilli la Dimension EuroQoL-5 dans une étude de sousgroupe auprès de patients consentants. Ils ont effectué des analyses statistiques pour comparer les résultats cliniques au fil du temps et d'après la situation des répondants.

RÉSULTATS : Les chercheurs ont recensé 298 patients dans la présente évaluation économique. Les participants, dont $56 \%$ étaient de sexe féminin, avaient un âge moyen ( \pm ÉT) de 53,7 $\pm 14,0$ ans. À l'admission, la DNe était présente depuis plus de cinq ans en moyenne. Les chercheurs ont observé les améliorations statistiquement significatives de tous les résultats cliniques de la douleur et de la qualité de vie liée à la santé entre le début de l'étude et les rendez-vous au bout d'un an. L'utilisation de nombreuses ressources de santé diminuait au fil du temps (p. ex., les rendez-vous à l'urgence ont diminué de moitié), ce qui favorisait des économiques globales. CONCLUSION : D'après les résultats, il faudrait faciliter l'accès aux centres universitaires de la douleur au Canada.
\end{abstract}

neuropathic pain $(\mathrm{NeP})$, specifically, were estimated to be $22 \%$ and $7 \%$, respectively. The same review identified 43 burden of illness studies, highlighting the negative impact of chronic pain on daily activities, health-related quality of life, productivity and health care use.
$\mathrm{D}$ e to its high prevalence and negative impact on health-related quality of life, the burden of chronic pain is an important public health problem globally. In a recent systematic review of 20 prevalence studies (1), average prevalence rates of chronic noncancer pain and ${ }^{1}$ Department of Clinical Epidemiology and Biostatistics, Faculty of Health Sciences, McMaster University; ${ }^{2}$ Programs for Assessment of Technology
in Health (PATH) Research Institute, St Joseph's Healthcare Hamilton, Hamilton; ${ }^{3}$ Departments of Clinical Neurological Sciences Eु
Anesthesia and Perioperative Medicine, Western University, London, Ontario; ${ }^{4}$ Department of Anesthesia, Pain Management and Perioperative
Medicine, Dalhousie University, Halifax, Nova Scotia; ${ }^{5} \mathrm{LW}$ Stitt Statistical Services; ${ }^{6}$ Wasser Pain Management Centre, University of Toronto,
Toronto; ${ }^{7}$ Department of Anesthesiology, University of Ottawa, Ottawa, Ontario; ${ }^{8}$ Fraser Health, Burnaby, British Columbia; ${ }^{9}$ Department of
Family Medicine, McGill University, Montreal, Quebec
Correspondence: Dr Jean-Eric Tarride, PATH Research Institute, St Joseph's Healthcare Hamilton, 25 Main Street West, Suite 2000, Hamilton,
Ontario L8P 1H1. Telephone 905-523-7284 ext 5281, fax 905-522-0568, e-mail tarride@mcmaster.ca 
According to the results of another recent study that used 2010 administrative data to evaluate the impact of $\mathrm{NeP}$ in five Western European countries (2), NeP was associated with an increased human and economic burden when compared with non-NeP. Similar results were observed in Canada (3).

While many patients experiencing chronic $\mathrm{NeP}$ will be referred to specialists at some point in time, very few studies have documented the long-term outcomes of the management of chronic $\mathrm{NeP}$ by pain specialists (1). Pain specialists generally take a more aggressive management approach than generalists to provide adequate pain relief; therefore, delays in access to specialist care may negatively impact patients' well-being (4). This is, for example, the case in Canada, where access to pain specialists is challenging $(4,5)$. To gain a better understanding of the value of pain management by pain specialists, a study was conducted in a Canadian, real-life setting to determine the long-term outcomes of the management of chronic NeP patients referred to Canadian academic pain centres for the management of their pain (6). We report the results of an analysis of a subset of these patients who participated in an economic study, which was designed to inform policy makers about the economic value of managing chronic pain in academic pain centres.

\section{Study design and population}

\section{METHODS}

The present article is an economic substudy of a one-year, prospective, multicentre cohort study (6) involving 789 patients with chronic noncancer NeP enrolled in seven academic centres in Canada (Calgary [Alberta], London, Hamilton, Toronto and Ottawa [Ontario], Montreal [Quebec] and Halifax [Nova Scotia]). The study, conducted between April 2008 and December 2011, received ethics approval by independent review boards representing each institution, and is registered at clinicaltrials.gov (NCT00669006) (6).

Patients with $\mathrm{NeP}$ were invited to participate in the study if they were $\geq 18$ years of age and had been referred to an academic multidisciplinary pain treatment facility for chronic $\mathrm{NeP}$ management. $\mathrm{NeP}$ was diagnosed if there was clinical evidence of a lesion or disease affecting the somatosensory system (7). The Douleur Neuropathique 4 (DN4) questionnaire was administered at baseline as a valid and reliable discriminator of $\mathrm{NeP}$ in support of this diagnosis (8). Exclusion criteria included: declining participation; chronic pain not primarily related to $\mathrm{NeP}$; presence of a personality disorder, cognitive impairment or a history of substance abuse; significant language barrier; presentation with progressive or recurrent cancer; presentation of fibromyalgia; and perineal pain of unknown etiology (eg, vulvodynia, vestibulitis). All enrolled patients reviewed, signed and dated the consent form before completing the questionnaires. Patient selfreported measurements were collected at baseline (ie, first visit at academic pain centre) and at three, six and 12 months following the baseline visit.

The present economic substudy included all patients entered into the main study from May 2009 onward, at which time two additional outcome measures, the EuroQoL-5 Dimension (EQ-5D) and an economic questionnaire were added. The economic evaluation was conducted from the perspective of public payers in Canada, as recommended by the Canadian Agency for Drugs and Technologies in Health Guidelines for the Economic Evaluation of Health Technologies (9).

\section{Instruments and outcomes}

During the baseline visit, participating patients were first invited to answer general questions (eg, age, sex, duration of $\mathrm{NeP}$ ), before answering standard outcome measures for chronic pain, as recommended by the Initiative on Methods, Measurement and Pain Assessment in Clinical Trials guidelines (10). In addition, the EQ-5D questionnaire and an economic questionnaire aimed at determining the direct costs associated with the management of chronic NeP were administered in the substudy. The following presents a brief description of the instruments considered in the economic substudy.

\section{Pain instruments}

The Brief Pain Inventory (BPI) was used to assess the intensity of the pain and its level of interference with daily activities (11). On a scale from 0 to 10 , mild pain was defined by a score of 0 to 3 , moderate pain by a score of 4 to 6 and severe pain by a score of 7 to 10 . The Pain Disability Index (PDI) was used to measure the impact of chronic pain on various aspects of life (12). The minimal index was 0 and the maximal index was 70; higher scores reflected greater pain-related disability. Although not specific to $\mathrm{NeP}$, a decrease of 8.5 to 9.5 points in the PDI score was deemed to be clinically important in patients with chronic back pain (13).

\section{Health-related quality of life instruments}

The Short Form-12 (SF-12) and the EQ-5D were used to measure health-related quality of life (HRQoL). The SF-12 questionnaire, a generic quality of life instrument, has been extensively used in clinical research and was chosen to measure participants' overall HRQoL (14). Summary scores for physical and mental health status were derived from the SF-12 (15). Scores $>50$ on the summary scale indicated a positive perception of health, while a score $<50$ indicated a negative perception. Differences of 2.5 to 5 points in physical or mental scores were considered to be clinically significant (1).

The EQ-5D is a validated HRQoL questionnaire, which is used in economic evaluations of health care programs to calculate quality adjusted life years. The EQ-5D measures health status in terms of five dimensions: mobility, self care, usual activity, pain/discomfort and anxiety/depression. Although single dimension scores are not available, the EQ-5D provides a weighted health index, the EQ-5D utility, ranging from 0 (death) to 1 (perfect health) (16). The United States weights were used in the present study (17). The minimally clinically-important difference for the EQ-5D has been reported in back pain to be 0.07 (18).

Patient global satisfaction with treatment and impression of change Patients were treated according to standard guidelines for the pharmacological management of $\mathrm{NeP}$ (19). Nonpharmacological treatments included physiotherapy, occupational therapy, chiropractic treatments, and local anesthetic or steroid injections. Satisfaction with chronic NeP-related treatment and impression of change were assessed using the Patient Global Satisfaction with Treatment and Impression of Change questionnaire (20). The first part of this questionnaire was related to the level of satisfaction, recorded at the time treatment was being received (on a scale from 0 to 10 ), while the second part of the questionnaire evaluated how chronic pain had changed since the beginning of the study on a 7-point Likert scale (from 'very much worse' to 'very much improved').

\section{Responder analysis}

Treatment response was defined as a 30\% reduction from baseline in average pain intensity on the BPI and a one point reduction in the Interference Scale Score of the BPI. This composite outcome measure recognizes clinically significant improvements in pain and function (21).

\section{Resource use and costs}

As commonly used by health economists to estimate resource use based on patient recall $(22)$, an economic questionnaire $(23,24)$ was administered to collect information regarding prescriptions and health care resources used due to chronic pain. This included visits to general practitioners, specialists, other health care practitioners, emergency rooms and hospitals, as well as any diagnostic tests or procedures (eg, Over the past three months, have you been admitted to a hospital overnight for your chronic pain?). The questionnaire was administered at baseline on referral to the academic pain centres, and again at three, six and 12 months. The time-recall period was three months at each time assessment. Various public sources from Ontario were consulted to determine the cost associated with the management of chronic NeP. The 2013 Ontario Schedule of Benefits (25), the 2013 Schedule of Laboratory (26) and the 2013 Drug Benefit Program (27) were used to 
TABLE 1

Baseline demographic characteristics $(n=298)$

\begin{tabular}{|c|c|}
\hline Female sex & 56.0 \\
\hline \multicolumn{2}{|l|}{ Age, years } \\
\hline Mean \pm SD & $53.7 \pm 14.0$ \\
\hline Median (minimum, maximum) & $54.0(21,88)$ \\
\hline \multicolumn{2}{|l|}{ Marital status } \\
\hline Married or common law & 68.9 \\
\hline Widowed & 5.1 \\
\hline Divorced or separated & 12.8 \\
\hline Never married & 13.2 \\
\hline Missing data, $\mathrm{n}$ & 2 \\
\hline \multicolumn{2}{|l|}{ Level of education } \\
\hline Primary school & 3.7 \\
\hline Secondary school & 34.5 \\
\hline College or university & 61.8 \\
\hline Missing, $\mathrm{n}$ & 2 \\
\hline \multicolumn{2}{|l|}{ Annual household income, \$ } \\
\hline$<20,000$ & 14.5 \\
\hline $20,000-35,000$ & 14.9 \\
\hline$>35,000-50,000$ & 18.1 \\
\hline$>50,000-80,000$ & 16.9 \\
\hline$>80,000$ & 35.5 \\
\hline Do not care to say, $\mathrm{n}$ & 48 \\
\hline Missing data, $\mathrm{n}$ & 2 \\
\hline \multicolumn{2}{|l|}{ Employment status } \\
\hline Full time & 25.4 \\
\hline Homemaker & 3.7 \\
\hline Laid off & 0.7 \\
\hline On disability & 31.2 \\
\hline Other & 2.7 \\
\hline Part time & 7.5 \\
\hline Retired & 23.4 \\
\hline Student & 1.4 \\
\hline Unemployed & 3.4 \\
\hline Volunteer & 0.7 \\
\hline
\end{tabular}

Data presented at \% unless otherwise indicated

assess the cost of visits to health care professionals and hospitals, procedures, and tests and medications, respectively. The costs associated with medications were calculated by identifying typical brands, dosage, forms and duration of treatment for each class of medications (eg, naproxen $[2 \times 500 \mathrm{mg}]$ for nonsteroidal anti-inflammatory drugs [NSAIDs]) and applying a best available price from the Ontario Drug Benefit Formulary. A mark-up of $8 \%$ and a monthly dispensing fee (ie, $\$ 8.62$ ) were added to the total cost for each prescription medication. All resources consumed were multiplied by their respective unit costs to calculate the cost of chronic NeP. The initial consultation and follow-up visits with pain specialists following referral to academic pain centres were also included in the determination of the costs.

\section{Statistical analyses}

Continuous variables were summarized using mean values and SDs, and discrete variables were represented using percentages. Missing data were entered using the last observation carried forward. The data were also analyzed using only complete observations (ie, without entering missing data) to ensure that results were similar. Paired $t$ tests and McNemar's $\chi^{2}$ tests were used to compare assessments across time for continuous (eg, BPI score) and dichotomous (eg, Have you been hospitalized due to chronic pain? [yes or no]) variables, respectively. The number of health care resources consumed over time was compared using a signed rank (nonparametric) test. All comparisons were performed against the baseline. To evaluate the homogeneity of the findings across sites, differences
TABLE 2

Pain duration, diagnosis and medication usage at baseline

\begin{tabular}{|c|c|}
\hline \multicolumn{2}{|l|}{ Pain duration, months } \\
\hline Mean \pm SD & $60.7 \pm 71.1$ \\
\hline Median (minimum, maximum) & $36.0(1,480)$ \\
\hline \multicolumn{2}{|l|}{ Diagnosis } \\
\hline Central & 8.7 \\
\hline Symmetrical polyneuropathy & 24.2 \\
\hline Mononeuropathy - trigeminal neuralgia & 5.7 \\
\hline Mononeuropathy - other & 38.9 \\
\hline Asymmetric polyneuropathy & 22.5 \\
\hline Medication & 89.9 \\
\hline Nonsteroidal anti-inflammatory drug & 57.4 \\
\hline Antidepressant (nonanalgesic) & 13.8 \\
\hline Antidepressant (analgesic) & 26.2 \\
\hline Anticonvulsant & 48.0 \\
\hline Muscle relaxant & 8.1 \\
\hline Benzodiazepine & 12.1 \\
\hline $\mathrm{N}$-methyl D-aspartate receptor antagonists & 0.3 \\
\hline Any opioid & 48.3 \\
\hline Opioid - long acting & 24.5 \\
\hline Opioid - slow acting & 36.2 \\
\hline Topical agents & 13.4 \\
\hline Cannabinoids & 11.4 \\
\hline Other & 13.1 \\
\hline \multicolumn{2}{|l|}{ Opioids* } \\
\hline $\mathrm{n}$ & 144 \\
\hline Mean \pm SD & $99.6 \pm 188.3$ \\
\hline Minimum & 0.08 \\
\hline Median & 40.0 \\
\hline Maximum & 1280 \\
\hline
\end{tabular}

Data presented as \% unless otherwise indicated. *Opioid dose expressed as morphine equivalent dose ( $m g /$ day)

among sites in terms of age, baseline pain intensity and pain duration were analyzed using ANOVA, with a Tukey-Kramer adjustment for pairwise comparisons. Among-site differences in the 12-month response rate were evaluated using a $\chi^{2}$ test.

The data were analyzed for all patients and by responder status at 12 months. In the present study, at least a 30\% reduction from baseline in average pain intensity on the BPI and a one point reduction in the Interference Scale Score of the BPI $(21,28)$ had to be observed at 12 months to be considered a responder. Differences in health care use between responders and nonresponders were made using Wilcoxon two-sample tests. To gain a better understanding of the determinants (eg, age) of the EQ-5D use and cost data over the 12-month study period, regression analyses were performed. Ordinary least squares models were used when the data were normal, whereas other types of models were considered in the absence of normality (eg, generalized linear model $[29,30])$. The following variables were considered in the regressions to explain the differences in use and cost data between month 12 and baseline: age, sex, marital status (married or single), education and income categories, pain severity at baseline, pain duration and responder status.

\section{RESULTS}

Patients' baseline characteristics

In the present economic substudy, 298 patients completed the baseline questionnaire. Almost two-thirds (68.1\%) of the participants were from Ontario, 13.8\% from Quebec, 13.4\% from Alberta and 4.7\% from Nova Scotia. The mean $( \pm \mathrm{SD})$ age of the participants was 53.7 years ( \pm 14.0 years), and $56.0 \%$ of the participants were female. The majority of the participants were married (68.9\%), had children $(78.6 \%)$, completed a college or university degree $(61.8 \%)$ and did not 


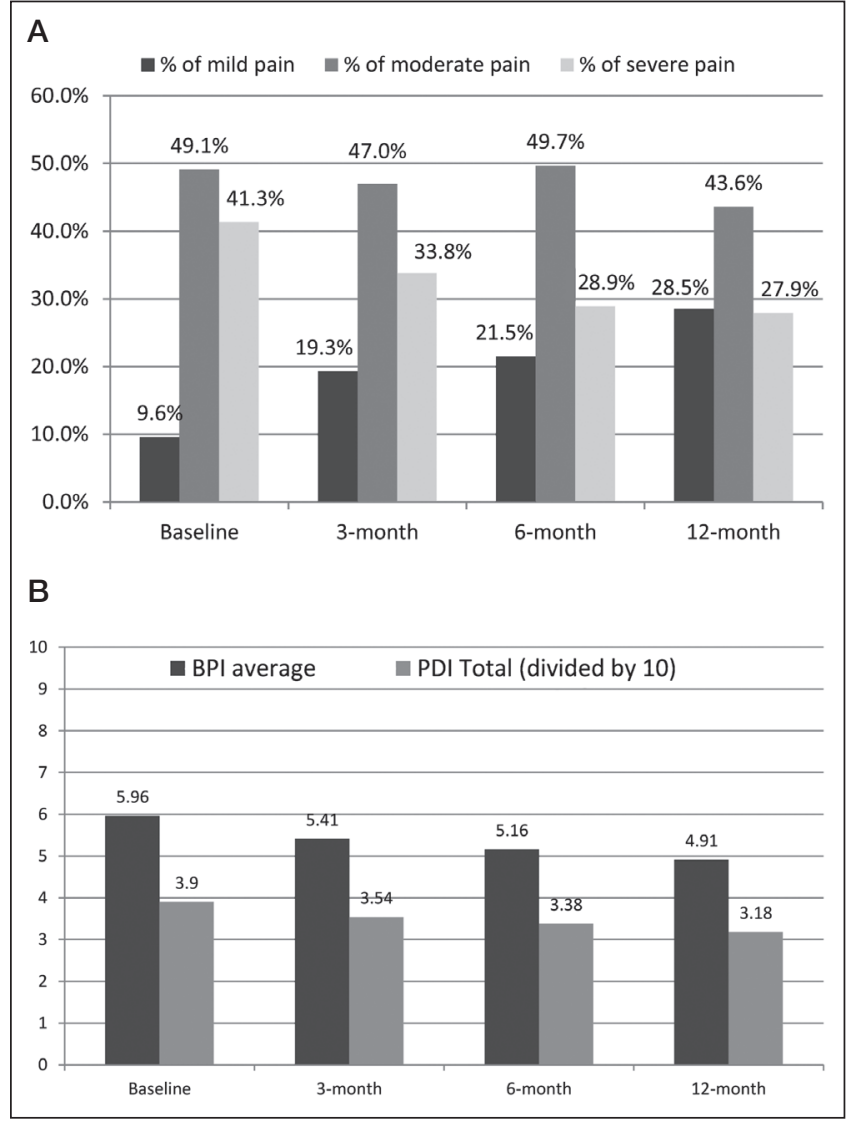

Figure 1) A Pain intensity levels over time; B Brief pain inventory (BPI) and Pain Disability Index (PDI) scores over time. All differences versus baseline statistically significant $(P<0.001)$

smoke (76.7\%). Based on the results from the 248 respondents who answered this question, $>50 \%$ of the participants had a household income $>\$ 50,000$ per year. More than $40 \%$ (41.5\%) of participants eligible for work (ie, not retired or students) were on disability $(31.2 \%$ out of $75.2 \%$ ). Table 1 presents the detailed data for key baseline characteristics. There was no difference among sites regarding pain duration $(\mathrm{P}=0.755)$. However, there was a difference among sites for mean age, with the Calgary site having older patients than Montreal and Ottawa $(\mathrm{P}=0.006)$. Sites also differed in terms of pain intensity, although no particular pairwise differences could be identified.

As reported in Table 2, the mean pain duration was $60.7 \pm 71.1$ months, and participants mostly suffered from mononeuropathy $(44.6 \%)$, symmetrical polyneuropathy $(24.2 \%)$ and asymmetric polyneuropathy (22.5\%). Most patients with mononeuropathies had a lumbosacral radiculopathy (often residual to failed back surgery syndrome) or a peripheral nerve entrapment. At the time of referral to the academic pain centres, $89.9 \%$ of the study participants were taking analgesic medications. The most commonly prescribed were NSAIDs (57.4\%), opioids (48.3\%), anticonvulsants (48.0\%) and analgesic antidepressants (26.2\%). NSAIDs were discontinued in most patients unless there was comorbid musculoskeletal or arthritic pain to justify their ongoing use. The mean daily morphine equivalent for those patients taking opioids at the time of referral was $99.6 \pm 188.3 \mathrm{mg}$. Table 2 presents more details regarding the treatments at baseline. When asked about their drug coverage, $>90 \%$ of the participants reported having prescription drug coverage through private or public plans, although out-of-pocket expenditures were estimated at approximately $30 \%$ of the prescription cost.

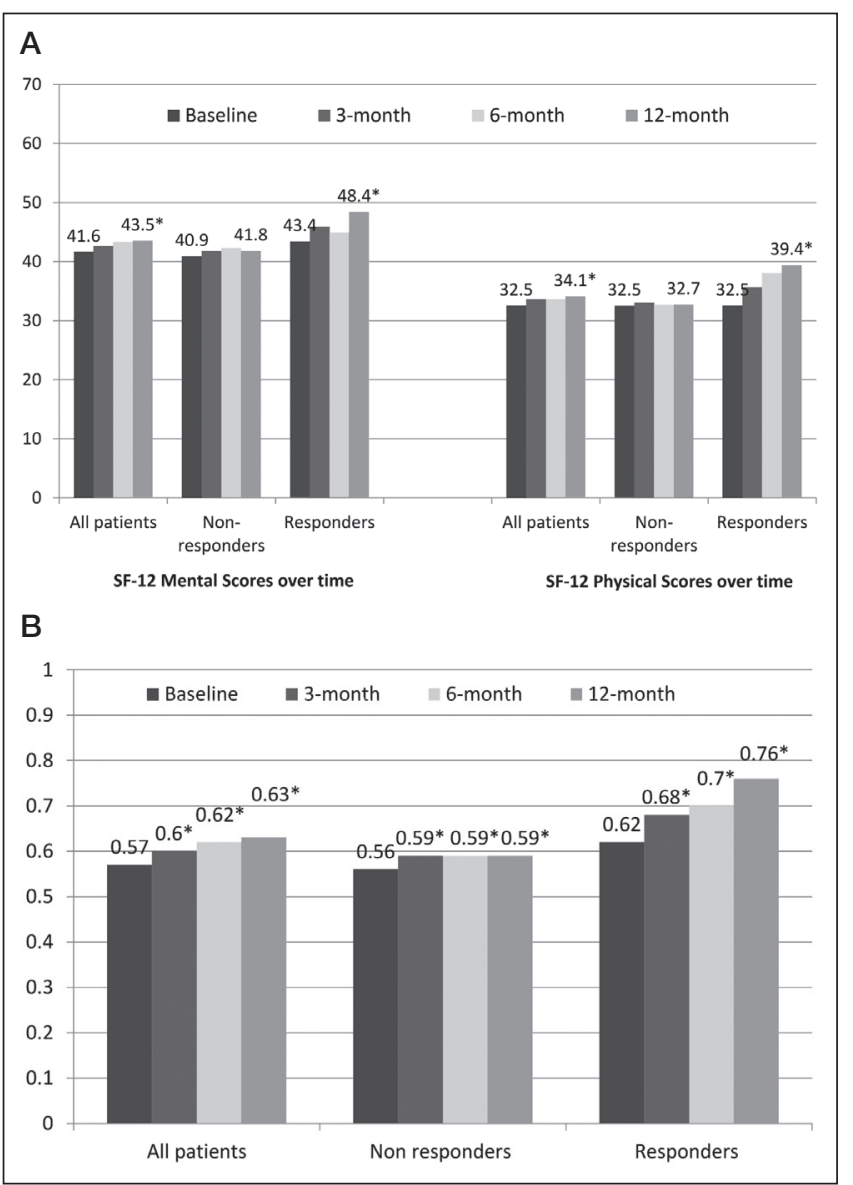

Figure 2) A Short Form-12 mental and physical scores over time; B EuroQoL-5 Dimension scores over time and according to pain intensity levels. ${ }^{*}$ Change from month 0 statistically significant $(P<0.05)$

Pain intensity and percentage of responders

There was a significant reduction in the pain intensity at all time points when measured in terms of pain intensity levels, BPI and PDI scores (Figures 1A and 1B). The number of participants experiencing severe pain significantly decreased from $41.3 \%$ at baseline to $27.9 \%$ at one year $(\mathrm{P}<0.001)$. At the same time, the number of participants experiencing mild pain significantly increased from $9.6 \%$ to $28.5 \%$ $(\mathrm{P}<0.0001)$. Over the one-year period, the BPI mean $( \pm \mathrm{SD})$ pain intensity score significantly decreased from $5.96 \pm 1.93$ to $4.91 \pm 2.29$ $(\mathrm{P}<0.001)$ and the PDI score from $39.0 \pm 16.9$ to $31.8 \pm 18.8(\mathrm{P}<0.001)$. Over the study period, $24.8 \%$ of study participants were responders at one year (ie, a $30 \%$ reduction from baseline in mean pain intensity on the BPI and a one point reduction on the interference scale score of the BPI). There was no difference among sites in terms of response rate $(\mathrm{P}=0.189)$.

\section{HRQoL}

The mean SF-12 mental score increased from $41.6 \pm 12.4$ at baseline to $43.5 \pm 11.9$ at one year $(\mathrm{P}=0.03)$, while the $\mathrm{SF}-12$ physical score increased from $32.5 \pm 9.9$ to $34.1 \pm 10.9(\mathrm{P}<0.001)$. On a scale from 0 (death) to 1 (full health), the EQ-5D utility increased from $0.57 \pm 0.22$ at baseline to $0.63 \pm 0.21(\mathrm{P}<0.001)$ at one year. Greater improvements $(\mathrm{P}<0.001)$ in the SF-12 and the EQ-5D were observed among responders (Figure 2A [SF-12] and 2B [EQ-5D]). For example, the EQ-5D utility associated with responders increased from $0.62 \pm 0.21$ at baseline to $0.76 \pm 0.16$ at one year, while the SF-12 physical score increased from $32.5 \pm 10.8$ to $39.4 \pm 11.8$ ( $P<0.001$ in both cases). No statistically significant differences in the SF-12 mental and physical scores and the EQ-5D utility data were observed among nonresponders between baseline and 
TABLE 3

Comparison of the three-month health care resource use preceding baseline and month-12 visit

\begin{tabular}{|c|c|c|c|c|c|c|}
\hline \multirow[b]{2}{*}{ Health care resource use } & \multicolumn{2}{|c|}{ Percentage } & \multirow[b]{2}{*}{$\mathbf{P}$} & \multicolumn{2}{|c|}{ Mean \pm SD } & \multirow[b]{2}{*}{$\mathbf{P}$} \\
\hline & Baseline visit & Month 12 & & Base line visit & Month 12 & \\
\hline Hospitalization & 3.00 & 1.00 & 0.146 & $0.040 \pm 0.243$ & $0.010 \pm 0.100$ & 0.065 \\
\hline Family doctor & 66.40 & 44.00 & $<0.001$ & $2.104 \pm 3.815$ & $1.060 \pm 1.685$ & $<0.001$ \\
\hline Medical specialist & 48.00 & 32.20 & $<0.001$ & $1.456 \pm 3.245$ & $0.735 \pm 1.760$ & $<0.001$ \\
\hline Pain management specialist & 29.20 & 31.50 & 0.576 & $0.638 \pm 1.667$ & $0.678 \pm 1.394$ & 0.425 \\
\hline Chiropractor & 9.10 & 8.10 & 0.749 & $0.705 \pm 3.034$ & $0.567 \pm 2.984$ & 0.224 \\
\hline Occupational therapist & 6.00 & 4.00 & 0.286 & $0.554 \pm 3.290$ & $0.248 \pm 2.177$ & 0.189 \\
\hline Blood tests & 13.80 & 8.40 & 0.04 & $0.695 \pm 3.824$ & $0.188 \pm 0.879$ & 0.001 \\
\hline Nerve conduction studies & 8.40 & 3.00 & 0.009 & $0.104 \pm 0.384$ & $0.037 \pm 0.236$ & 0.006 \\
\hline X-rays & 15.10 & 6.40 & $<0.001$ & $0.560 \pm 2.372$ & $0.124 \pm 0.593$ & $<0.001$ \\
\hline Computed tomography scan & 7.10 & 3.00 & 0.036 & $0.101 \pm 0.414$ & $0.057 \pm 0.419$ & 0.133 \\
\hline
\end{tabular}

one year. Because the difference in utility data between the baseline and one-year visit was normal, ordinary least square regressions were used. According to these analyses, age, sex, marital status, education and income categories, pain severity at baseline, pain duration and responder status were not predictors of the change in EQ-5D utility over time.

Satisfaction with treatment and impression of change

In terms of prescription patterns following referral to pain academic centres, the percentage of patients being treated with analgesic antidepressants and anticonvulsants did not change significantly between baseline and one year. This was consistent with clinical practice, where clinicians routinely switch analgesics in some patients and customize doses to optimize analgesia and minimize adverse effects. However, the proportion of users of long-acting opioids increased from $24.5 \%$ at baseline to $32.2 \%$ at one year $(\mathrm{P}<0.001)$. The proportion of other drug classes did not change significantly over time, with the exception of cannabinoid use, which increased from $11.4 \%$ at baseline to $15.8 \%$ at one year $(\mathrm{P}<0.01)$. On a scale from 0 to 10 , satisfaction with $\mathrm{NeP}$ treatment increased from $6.0 \pm 3.1$ at baseline to $6.9 \pm 3.7$ at one year $(\mathrm{P}<0.001)$. Statistically significant differences were also observed at three and six months postbaseline. Over time, 35.2\% of all patients participating in the economic substudy indicated that their condition was 'much improved' or 'very much improved', and this proportion was statistically higher in the responder group than in the nonresponder group (ie, $75.7 \%$ versus $20.9 \%$, respectively; $\mathrm{P}<0.001$ ).

Health care resource use and costs

Compared with the three-month resource use before the baseline visit, there was a significant reduction at one year in the percentage of emergency room visits ( $15.4 \%$ at baseline to $6.7 \%$ at 12 months), family doctor visits $(66.4 \%$ to $44.0 \%)$, walk-in clinics ( $9.7 \%$ to $3.7 \%$ ), medical specialists $(48.0 \%$ to $32.2 \%)$ and physical therapists $(21.5 \%$ to $12.8 \%)$. Here, medical specialists included other specialties not specified in the questionnaire provided to the subjects, such as neurologists, rheumatologists, cardiologists, surgeons, endocrinologists, chiropodists, anesthesiologists, internal medicine, physiatrists and podiatrists. The number of tests and procedures also significantly decreased over time with respect to blood tests (from $13.8 \%$ to $8.4 \%$ ), nerve conduction studies ( $8.4 \%$ to $3.0 \%$ ), $\mathrm{x}$-rays ( $15.1 \%$ to $6.4 \%$ ) and magnetic resonance imaging (MRI) scans ( $11.1 \%$ to $5.7 \%)$. In addition to the decrease in use, a statistically significant reduction in the mean number of visits was also observed for all these services. Table 3 presents the details regarding the use (eg, percentage use and mean use) of the health care resources consumed by $>5 \%$ of the participants. Although a minority of participants $(<5 \%$ for each of the following categories) identified having consulted other health care professionals (eg, dieticians, acupuncturist, massage therapy) or undergone some treatments (eg, local anesthetic infusion, botox, surgery), no statistical differences in use were observed over time. Similarly, there were no statistically significant differences between responders and nonresponders in terms of health care resource use, except for the use of MRI $(\mathrm{P}=0.010)$.

The average three-month costs preceding the baseline visit and the 12 -month visit were calculated to be $\$ 1,139.20$ and $\$ 840.70$ per patient, respectively, and this difference was statistically significant $(\mathrm{P}<0.001)$. This occurred despite an increase in medication costs from $\$ 281.7$ to $\$ 357.20$ ( $\mathrm{P}<0.001$ [signed rank test]). Table 4 presents this information for all patients and per responder status for the major cost categories. Although the relative cost reduction appeared to be greater in responders, these differences were not statistically significant $(P=0.429)$. In all analyses, costs were statistically greater with increased pain severity at baseline $(\mathrm{P}=0.017)$ and at one year $(\mathrm{P}<0.001)$. However, pain intensity was not identified as a predictor of the change in the three-month costs over time when controlling for other variables (eg, age, sex, responder status).

\section{CONCLUSIONS}

The results of the present study indicate that access to care at interdisciplinary academic pain centres was cost saving and improved health outcomes.

This adds to the body of evidence related to the human and economic burden of chronic NeP, and the economic benefits of a pain management program initiated in academic centres because few studies have examined optimal treatment of chronic $\mathrm{NeP}$ in the real world (1). While not directly comparable, some of our results are consistent with other Canadian studies. For example, our population was comparable with the population enrolled in a recent Canadian study evaluating 728 chronic pain patients on the waitlists of multidisciplinary pain treatment facilities in Canada (4). In this study and in our study, patients were in their early 50s, and 30\% to $40 \%$ were unable to work due to disability or illness. In both studies, between $40 \%$ and $60 \%$ of participants rated their average pain in the past week as severe, and HRQoL was low compared with the general population. The present study revealed that mean monthly cost per patient was $\$ 3,112$, of which the vast majority were costs due to patients or caregivers' time lost from labour and leisure. Costs due to health care appointments, hospitalization and medications, paid by public payers $(\$ 155)$, private insurances $(\$ 126)$ or by patients $(\$ 118)$ were estimated to be $\$ 399$ per month (28) or $\$ 1,197$ for three months, which is comparable to our 
TABLE 4

Comparison of three-month mean costs at month 0 and month 12

\begin{tabular}{|c|c|c|c|c|c|c|}
\hline \multirow{2}{*}{ Health care resources } & \multicolumn{3}{|c|}{ Month 0} & \multicolumn{3}{|c|}{ Month 12} \\
\hline & $\begin{array}{l}\text { All participants } \\
\quad(n=298)\end{array}$ & \multicolumn{2}{|c|}{ Responder status } & $\begin{array}{l}\text { All participants } \\
(n=298)\end{array}$ & \multicolumn{2}{|c|}{ Responder status } \\
\hline Emergency room visits & 73.50 & 65.70 & 81.70 & 33.80 & 41.90 & 7.80 \\
\hline Walk-in clinic visits & 15.80 & 16.10 & 14.60 & 5.70 & 7.90 & 1.00 \\
\hline Psychotherapists & 7.40 & 9.80 & 0.00 & 21.60 & 26.30 & 8.50 \\
\hline Dental specialist & 1.80 & 0.80 & 5.30 & 1.60 & 0.00 & 6.30 \\
\hline Physiotherapist & 125.60 & 144.10 & 72.90 & 49.70 & 58.80 & 36.50 \\
\hline Occupational therapist & 83.10 & 118.00 & 4.10 & 37.30 & 44.40 & 26.40 \\
\hline Osteopath & 4.80 & 3.90 & 8.50 & 2.10 & 0.90 & 6.10 \\
\hline Massage therapist & 19.60 & 25.10 & 9.10 & 14.90 & 18.90 & 6.10 \\
\hline Chiropractor & 86.00 & 97.70 & 42.90 & 69.20 & 64.00 & 70.90 \\
\hline Acupuncturist & 9.40 & 13.60 & 0.00 & 2.80 & 3.50 & 1.80 \\
\hline Tests & 102.50 & 101.70 & 104.80 & 55.00 & 63.20 & 39.50 \\
\hline Medications & 281.70 & 298.80 & 210.50 & 357.20 & 383.20 & 251.90 \\
\hline Total costs & $1,139.20$ & $1,210.90$ & 868.30 & 840.70 & 928.00 & 601.00 \\
\hline $\begin{array}{l}\text { Difference in 3-month costs: } \\
12 \text {-month versus baseline visits }\end{array}$ & & & & -298.5 & -282.9 & -267.3 \\
\hline Relative reduction, \% & & & & -26.2 & -23.3 & -30.8 \\
\hline
\end{tabular}

Data presented in \$ unless otherwise indicated

three-month estimate of $\$ 1,139$ before the referral visit. Two other Canadian $\mathrm{NeP}$ studies have also reported similar direct costs associated with $\mathrm{NeP}(3,24)$. These results are consistent with the results of studies conducted in other jurisdictions, all demonstrating that chronic NeP pain imposes a large burden to our society. However, the present study was one of the first to evaluate a pain management strategy initiated at academic pain centres in terms of HRQoL and costs.

There were several limitations associated with the present study. First, our sample size for the subset of patients who provided HRQoL and economic data was relatively small. In addition, our study population of chronic pain patients observed in pain academic centres represents only a small proportion of all the chronic pain patients in Canada. In addition, the present study was conducted in academic pain centres, which may not be representative of all pain centres in Canada. The study design also had some limitations due to its pre-post design. Ideally, outcomes (eg, EQ-5D, resource use) should have been measured one year before referral, at referral and one year after referral, to better control for patient history. However, this was not possible because data collection started at the time of the first visit to the academic pain centre. In addition, costs were derived from resource-use data, which were based on patient recall over a three-month time period. This may have introduced some uncertainty in the results. However, in the absence of access to administrative data or collection of diaries, this method of collecting data is commonly accepted. As a reference, Statistics Canada population health surveys (eg, Canadian Community Health Surveys [31]) uses a time recall period of one year for the questions related to the use of health care resources (eg, number of hospitalizations over the last year). In contrast, we used a period of three months to minimize patient recall bias. Furthermore, we evaluated the intervention in terms of the difference over time in costs and outcomes, which should also mitigate this issue (eg, focusing on the difference of two values evaluated with the same recall bias rather than focusing on the absolute values at baseline and one year). Finally, due to the payer perspective chosen for this economic evaluation and to minimize the patient burden associated with answering many questionnaires, we did not consider indirect costs, such as time lost from work or leisure, which have been revealed to be substantial in chronic pain studies (1). Evaluating the impact of pain management from a broader perspective, taking into account indirect costs is an important area for future research. Finally, there could be differences between sites that may affect the generalizability of the present study.

Despite these limitations, the results of the present study conducted in a real-life setting reveal that treating chronic NeP patients in academic pain centres has the potential to reduce health care resource use and to improve health outcomes. Considering that patient health deteriorates while being on waiting lists, access to pain specialists in Canada should be encouraged. More research is also needed to measure the impact of pain management strategies on patients, their families and friends, and the overall society.

ACKNOWLEDGEMENTS: The authors thank Donna Wilcockson for her help in formatting the manuscript, as well as Josie Visentini PhD, for her valuable comments.

FINANCIAL SUPPORT: This study was funded by the Canadian Foundation for Innovation (\#7878) and Pfizer Canada.

\section{REFERENCES}

1. Andrew R, Derry S, Taylor RS, Straube S, Phillips CJ. The costs and consequences of adequately managed chronic non-cancer pain and chronic neuropathic pain. Pain Pract 2014;14:79-94.

2. Langley PC, Van LC, Cappelleri JC, Carroll D. The burden associated with neuropathic pain in Western Europe.

J Med Econ 2013;16:85-95.

3. Lachaine J, Gordon A, Choiniere M, Collet JP, Dion D, Tarride JE. Painful neuropathic disorders: An analysis of the Regie de l'Assurance Maladie du Quebec database. Pain Res Manag 2007;12:31-7.

4. Choiniere M, Dion D, Peng P, et al. The Canadian STOP-PAIN project - Part 1: Who are the patients on the waitlists of multidisciplinary pain treatment facilities? Can J Anaesth 2010;57:539-48. 
5. Peng P, Choiniere M, Dion D, et al. Challenges in accessing multidisciplinary pain treatment facilities in Canada. Can J Anaesth 2007;54:977-84.

6. Moulin D, Clark A, Gordon A, et al. Canadian multi-centre cohort study to determine the long-term outcomes of the management of chronic neuropathic pain. Pain Res Manag 2013;18:97-101.

7. Treede RD, Jensen TS, Campbell JN, et al. Neuropathic pain: Redefinition and a grading system for clinical and research purposes. Neurology 2008;70:1630-5.

8. Bouhassira D, Attal N, Alchaar H, et al. Comparison of pain syndromes associated with nervous or somatic lesions and development of a new neuropathic pain diagnostic questionnaire (DN4). Pain 2005;114:29-36.

9. Canadian Agency for Drugs and Technologies in Health. Guidelines for the Economic Evaluation of Health Technologies: Canada, 3rd edn. Ottawa: 2006.

10. Turk DC, Dworkin RH, Allen RR, et al. Core outcome domains for chronic pain clinical trials: IMMPACT recommendations. Pain 2003;106:337-45.

11. Cleeland CS, Ryan KM. Pain assessment: Global use of the brief pain inventory. Ann Acad Med Singapore 1994;23:129-38.

12. Chibnall JT, Tait RC. The pain disability index: Factor structure and normative data. Arch Phys Med Rehabil 1994;75:1082-6.

13. Soer R, Reneman MF, Vroomen PC, Stegeman P, Coppes MH. Responsiveness and minimal clinically important change of the Pain Disability Index in patients with chronic back pain. Spine (Phila Pa 1976) 2012;37:711-5.

14. Melzack R. The short-form McGill Pain Questionnaire. Pain 1987;30:191-7.

15. Ware J, Kosinski M, Dewey J. How to score version two of the SF-36 health survey. Lincoln (RI): QualityMetric Inc; 2000.

16. Drummond M, O'Brien B, Stoddart G, et al. The EuroQol EQ-5D. Methods for the Economic Evaluation of Health Care Programmes. Toronto: Oxford University Press; 1997.

17. U.S. valuation of the EuroQol EQ-5D health states. Rockville (MD): Agency for Healtcare Research and Quality; 2012.

18. Brazier J, Roberts J, Tsuchiya A, Busschbach J. A comparison of the EQ-5D and SF-6D across seven patient groups. Health Econ 2004;13:873-84.

19. Moulin D, Boulanger A, Clark AJ, et al. Pharmacological management of chronic neuropathic pain: Revised consensus statement from the Canadian Pain Society. Pain Res Manag 2014;19:328-35.

20. Sullivan M, Bishop S, Pivik J. The pain catastrophizing scale: Development and validation. Psychological Assessment 1995;7:524-32.

21. Dworkin RH, Turk DC, McDermott MP, et al. Interpreting the clinical importance of group differences in chronic pain clinical trials: IMMPACT recommendations. Pain 2009;146:238-44.

22. Ridyard CH, Hughes DA. Development of a database of instruments for resource-use measurement: Purpose, feasibility, and design. Value Health 2012;15:650-5.

23. Tarride JE, Blackhouse G, De RG, et al. Cost-effectiveness analysis of elective endovascular repair compared with open surgical repair of abdominal aortic aneurysms for patients at a high surgical risk: A 1-year patient-level analysis conducted in Ontario, Canada. J Vasc Surg 2008;48:779-87.

24. Tarride J, Collet J, Choiniere M, Rousseau C, Gordon A. The economic burdenof neuropathic pain in Canada. J Med Econ 2006;9:55-68

25. Ministry of Health and Long-Term Care. Schedule of benefits for physician services under the Health Insurance Act. Toronto: Ministry of Health and Long-Term Care; 2013.

26. Ministry of Health and Long-Term Care. Ontario Health Insurance (OHIP) schedule of benefits and fees. Schedule of benefits for laboratory services. Toronto: Ministry of Health and Long-Term Care; 2013.

27. Ministry of Health and Long-Term Care. Ontario Drug Benefit Formulary/Comparative Drug Index. Toronto: Ministry of Health and Long-Term Care; 2015.

28. Dworkin RH, Turk DC, Wyrwich KW, et al. Interpreting the clinical importance of treatment outcomes in chronic pain clinical trials: IMMPACT recommendations. J Pain 2008;9:105-21.

29. Manning WG, Mullahy J. Estimating log models: To transform or not to transform? J Health Econ 2001;20:461-94.

30. Moran JL, Solomon PJ, Peisach AR, Martin J. New models for old questions: Generalized linear models for cost prediction. J Eval Clin Pract 2007;13:381-9.

31. Statistics Canada. Access to Health Care Services and Waiting Times. Ottawa: Statistics Canada; 2013. 


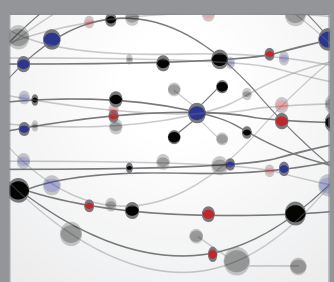

The Scientific World Journal
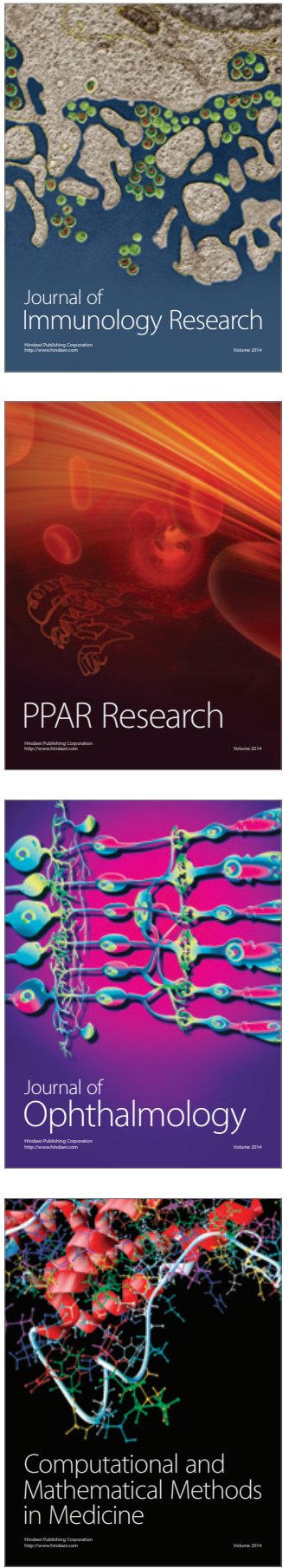

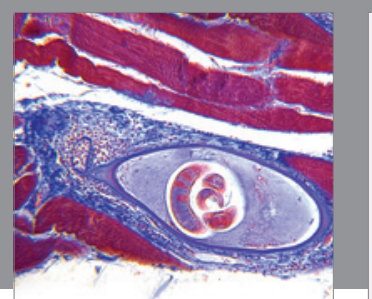

Gastroenterology Research and Practice

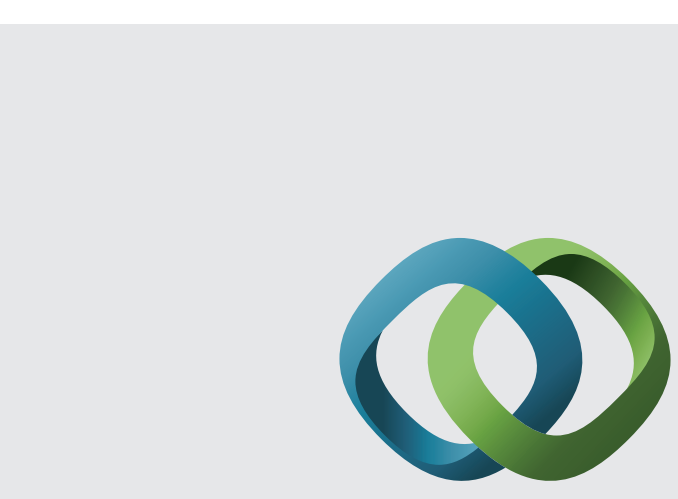

\section{Hindawi}

Submit your manuscripts at

http://www.hindawi.com
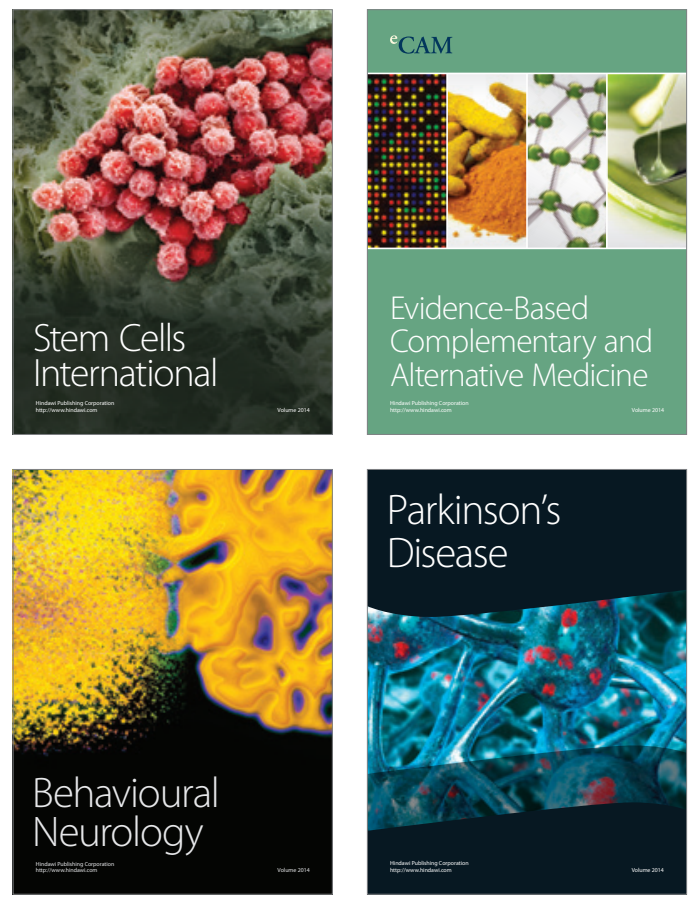
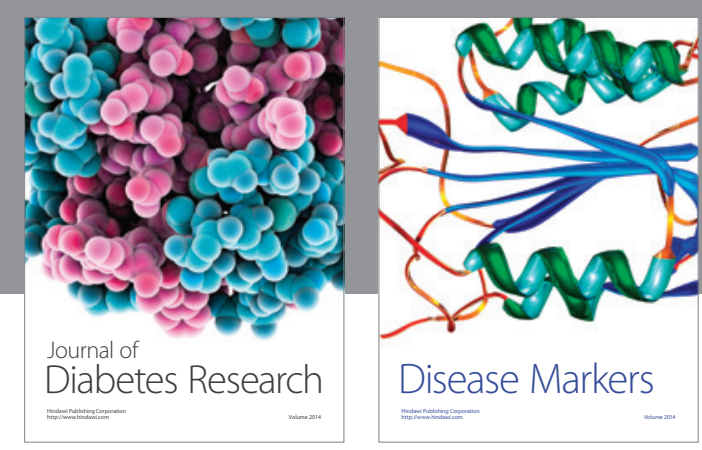

Disease Markers
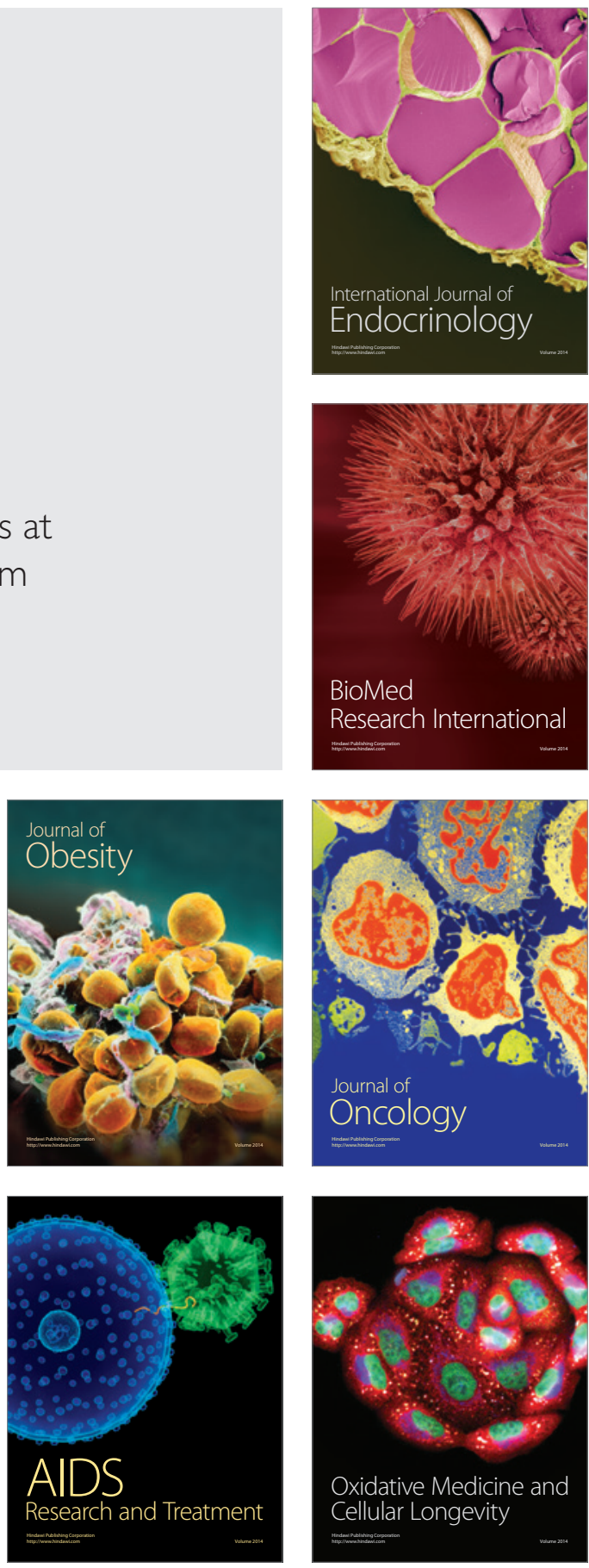